\title{
Influence of the device architecture to the ITO surface treatment effects on organic solar cell performance
}

\author{
C. Y. Kwong, ${ }^{1}$ A. B. Djurišici ${ }^{1,2}$, P. C. Chui, ${ }^{1}$ and W. K. Chan ${ }^{3}$ \\ ${ }^{1}$ Department of Electrical \& Electronic Engineering, University of Hong Kong, \\ Pokfulam Road, Hong Kong \\ ${ }^{2}$ Department of Physics, University of Hong Kong, \\ Pokfulam Road, Hong Kong \\ ${ }^{3}$ Department of Chemistry, University of Hong Kong, \\ Pokfulam Road, Hong Kong
}

\begin{abstract}
In this work, we investigate the influence of different indium tin oxide (ITO) surface treatments on the performance of organic solar cells with different device architectures. Two layer cells with different layer hierarchy (ITO/copper phthalocyanine $(\mathrm{CuPc}) /$ fullerene $\left(\mathrm{C}_{60}\right) / \mathrm{Al}$ and $\left.\mathrm{ITO} / \mathrm{C}_{60} / \mathrm{CuPc} / \mathrm{Cu}\right)$ and three layer cells with mixed layer inserted between $\mathrm{CuPc}$ and $\mathrm{C}_{60}$ were fabricated. We found that in all cases the short circuit current was the parameter which was most significantly affected by ITO surface treatment. However, the performance of the cells with $\mathrm{C}_{60}$ layer in contact with ITO was markedly less sensitive to the ITO surface treatments compared to the cells with $\mathrm{CuPc}$ in contact with ITO. The cells with $\mathrm{C}_{60}$ layer in contact with ITO also exhibited higher efficiency compared to the cells with CuPc in contact with ITO. We also fabricated two layer cells with structures $\mathrm{ITO} / \mathrm{CuPc} /$ perylene tetracarboxylic acid diimide (PTCDI)/Al and ITO/PTCDI/CuPc/Cu. In this case, we also obtain higher efficiency and lower sensitivity to ITO properties when "n type" material is in contact with ITO. The best obtained AM1 power conversion efficiency was $0.4 \%$ for ITO/PTCDI/CuPc/Cu cell and $\mathrm{ITO} / \mathrm{C}_{60} / \mathrm{CuPc}: \mathrm{C}_{60} / \mathrm{CuPc} / \mathrm{Cu}$ cells.
\end{abstract}

Keywords: organic solar cells, copper phthalocyanine, ITO treatments

\section{INTRODUCTION}

Indium tin oxide (ITO) is a commonly used substrate for the fabrication of organic optoelectronic devices. ITO properties are highly dependent on the deposition conditions, as well as post-deposition surface treatments. While there are a number of studies on the influence of ITO surface treatments on the ITO properties and the performance of organic light emitting diodes (OLEDs) ${ }^{1-10}$ studies on influence of the ITO surface treatments to solar cell performance have been scarce. ${ }^{11}$ It is well known that various (plasma, chemical etc.) surface treatments significantly affect the work function, sheet resistance, and surface roughness and morphology of the ITO, at present influence of these factors to the solar cell performance is not fully clear. Oxidative treatments, such as oxygen plasma ${ }^{1-3}$ or UV ozone, ${ }^{7}$ increase the work function of ITO and thusly improve the OLED performance. Carbon contamination removal, ${ }^{7-9}$ creation of surface states near and possibly below the bottom of the conduction band, ${ }^{2}$ change of the ratio of surface constituents, ${ }^{10}$ Fermi level shift, ${ }^{10}$ and possible formation of surface dipoles ${ }^{10}$ were proposed as possible mechanisms responsible for the work function increase with the oxidative treatments. For the work function increase (decrease) with acid (base) surface treatment, formation of surface dipoles was proposed. ${ }^{4,5}$ For phthalocyanine based Schottky barrier solar cells, it was found that the ITO surface treatments influence the cell performance, mainly by changing the short circuit current. ${ }^{11}$

In this work, we investigate the influence of the ITO surface treatments on the performance of two layer solar cells. We have chosen to use copper phthalocyanine $(\mathrm{CuPc})$ and fullerene $\left(\mathrm{C}_{60}\right)$, since combination of phthalocyanine derivatives and $\mathrm{C}_{60}$ is commonly used in organic solar cells. ${ }^{12-14}$ The influence of the layer thickness on the cell performance in the $\mathrm{CuPc} / \mathrm{C}_{60}$ double layer cells was studied in detail, ${ }^{13}$ so that this combination represents a good model cell to study the influence of the ITO substrate treatments. Since it was shown previously that inverted hierarchy (i.e. "n type" organic layer in contact with ITO instead of a "p type" organic) produces improved device performance, ${ }^{15-17}$ we investigated both ITO/ 
$\mathrm{CuPc} / \mathrm{C}_{60} / \mathrm{Al}$ and $\mathrm{ITO} / \mathrm{C}_{60} / \mathrm{CuPc} / \mathrm{Cu}$ device architectures. Since in the former structure ITO acts as a hole collector, and in the latter as electron collector, it is expected that the surface treatments will have different influence in these two structures. It was found that the inverted cells exhibit improved performance and lower sensitivity to the ITO properties. The improved performance in the inverted dye hierarchy was previously attributed to improved Förster energy transfer when shorter wavelength absorber is placed in contact with transparent electrode surface. ${ }^{15,18}$ However, observed differences in the influence of ITO properties to the performance of cells with different hierarchy indicate that other mechanisms also contribute to improved efficiency of inverted cells.

In order to verify whether improved performance and less sensitivity to the ITO parameters is a general feature of the inverted device structure, we also fabricated $\mathrm{ITO} / \mathrm{CuPc} /$ perylene tetracarboxylic acid diimide (PTCDI)/Al and ITO/PTCDI/CuPc/Cu cells. For this material system as well we obtained improved performance for inverted hierarchy. Finally, we fabricated a three layer ITO $/ \mathrm{C}_{60} / \mathrm{CuPc}: \mathrm{C}_{60} / \mathrm{CuPc} / \mathrm{Cu}$ cell and performed six different surface treatments in order to identify the role of surface treatment. $0.4 \%$ AM1 power conversion efficiency was obtained for ITO/PTCDI (20nm) $/ \mathrm{CuPc}(25 \mathrm{~nm}) / \mathrm{Cu}$ cell and $\mathrm{ITO} / \mathrm{C}_{60}(10 \mathrm{~nm}) / \mathrm{CuPc}: \mathrm{C}_{60}(60 \mathrm{~nm}) / \mathrm{CuPc}(10 \mathrm{~nm}) / \mathrm{Cu}$ cells. Possible mechanisms for the observed performance improvement are the removal of contamination of the ITO surface, change in the density of defects and traps affecting the charge collection at ITO/organic interface, change in the Fermi level alignment of the organic layer, and changes in growth mode of the organic layer affecting the organic/organic interface and the exciton dissociation efficiency. The paper will be organized as follows. In the following section, experimental details are described. In Section 3 , obtained results for different surface treatments, different materials used, and different device structures and are presented and discussed. Finally, conclusions are drawn.

\section{EXPERIMENT}

The devices were made using high purity $\mathrm{CuPc}$ powder which had been purchased from Strem Chemicals, $\mathrm{C}_{60}$ which had been purchased from Materials and Electrochemical Research Corp. (Tucson, AZ), and PTCDI purchased from Tokyo Kasei Kogyo Co., Ltd. ITO glass substrates with surface sheet resistance $\sim 10 \Omega$ /square were supplied by China Southern Glass Holding Co. Ltd., Shenzhen, China. Prior to evaporation, ITO substrates were cleaned. The cleaning procedure consisted of first rubbing with cotton and acetone, cotton and ethanol, then cleaning in ultrasonic bath for 10 minutes in toluene, acetone, ethanol, and deionized water consecutively. The cleaning in ultrasonic bath was repeated until the substrates were clean, and the substrates were dried in the oven. If no surface treatment other than cleaning with organic solvents as described above is performed, ITO substrates will be referred to as untreated or as-cleaned substrates. Acid or base treatment was performed by dipping the substrates into $4 \%$ aqueous acid (base) solution for 1 minute. The acid used was $\mathrm{HCl}$, since it produced good results for Schottky barrier solar cells. ${ }^{11}$ The base used was NaOH. UV ozone treatment was done for ten minutes, with $12 \mathrm{~cm}$ distance between $20 \mathrm{~W}$ UV light source and the sample. Mechanical treatment (mech.) has been performed using clean room wiper rubbing, followed by ultrasonic cleaning with DI water.

The films were evaporated in high vacuum. Pressure during evaporation was of the order $10^{-4} \mathrm{~Pa}$. The evaporation rate was $1-2 \AA / s$. The distance from source to film was about $23 \mathrm{~cm}$ to ensure uniformity of film thickness, and the substrate holder was rotating. The thickness of the films was controlled using quartz thickness monitor. After evaporation, film thickness was verified using a Dektak 3 step profiler. In all the devices, CuPc layers were doped with $\mathrm{C}_{60}$ in 20:1 ratio. PTCDI and $\mathrm{C}_{60}$ layers were undoped. The layer thickness in two layer devices was $40 \mathrm{~nm}$, with exception of PTCDI where $20 \mathrm{~nm}$ was used due to its short exciton diffusion length. For the comparison of different ITO surface treatments, the substrates treated in different manners were placed on the sample holder and all the devices on four different substrates were fabricated during the same deposition process. Eight cells were fabricated on each substrate. The current-voltage characteristics were measured using a Keithley 2400 sourcemeter. For white light efficiency measurements, Oriel 66002 xenon arc lamp with AM1 filter was used. The light intensity was $98 \mathrm{~mW} / \mathrm{cm}^{2}$. For I-V characteristics measurement, ITO was connected to the positive end of the source meter for the conventional hierarchy, while for the inverted hierarchy ITO was connected to the negative end of the source meter. 


\section{RESULTS AND DISCUSSION}

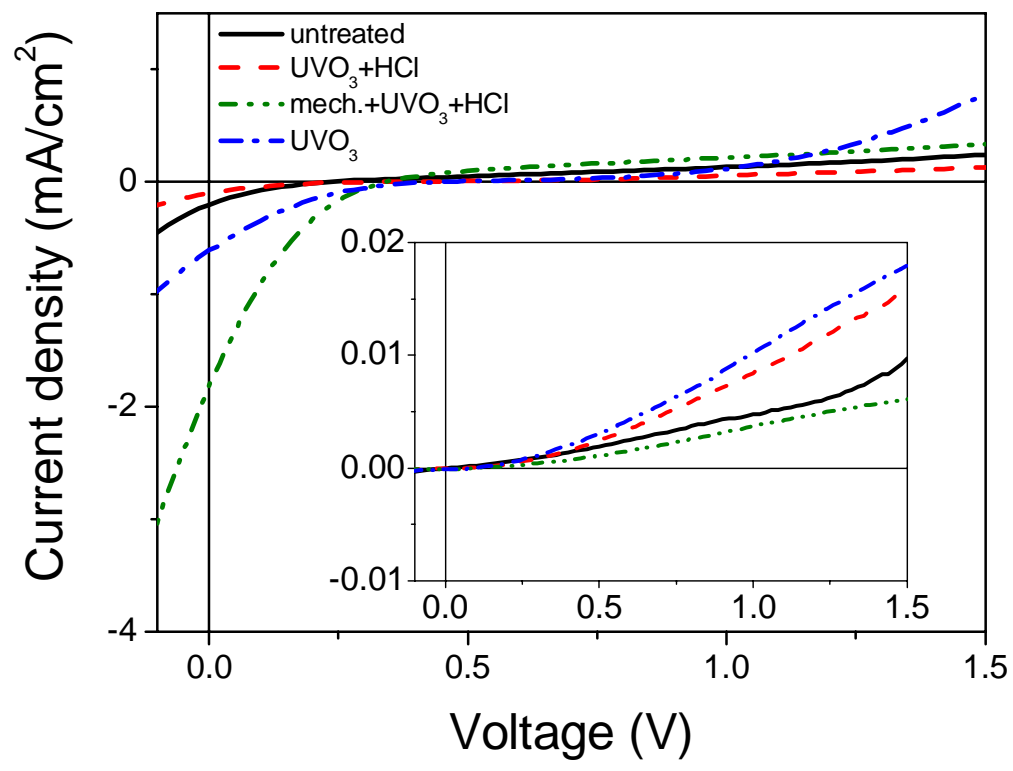

Fig. 1 The current-voltage characteristics of ITO/CuPc/ $\mathrm{C}_{60} / \mathrm{Al}$ cells with different ITO surface treatments under AM1 illumination. The inset shows dark current vs. voltage.

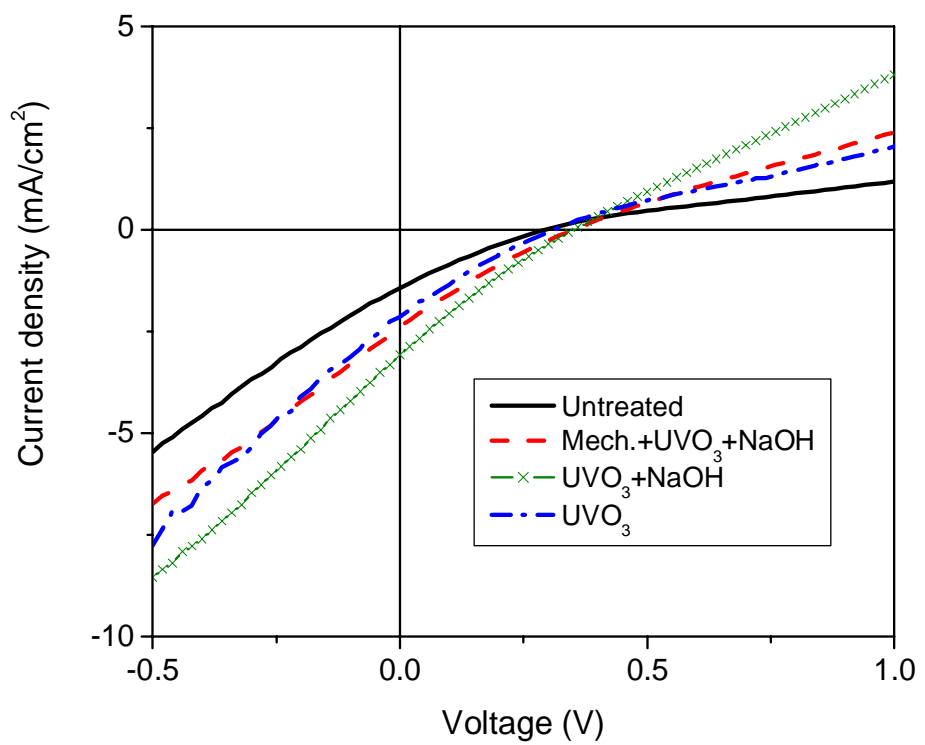

Fig. 2 The current-voltage characteristics of ITO $/ \mathrm{C}_{60} / \mathrm{CuPc} / \mathrm{Cu}$ cells with different ITO surface treatments under AM1 illumination. 
Figure 1 shows the current voltage characteristics of the ITO/CuPc$(40 \mathrm{~nm}) / \mathrm{C}_{60}(40 \mathrm{~nm}) / \mathrm{Al}$ solar cell for different ITO surface treatments. The obtained AM1 power conversion efficiency is $0.008 \%$ for untreated substrate, $0.004 \%$ for UV ozone $+\mathrm{HCl}, 0.093 \%$ for mech. $+\mathrm{UV}$ ozone $+\mathrm{HCl}$, and $0.035 \%$ for $\mathrm{UV}$ ozone only treated substrate. Fill factor is not affected by the ITO surface treatment. The open circuit voltage shows small dependence on the ITO surface treatment, however the change in the open circuit voltage (from $0.22 \mathrm{~V}$ for untreated to $0.44 \mathrm{~V}$ for UV ozone treated cell) does not appear to be related to ITO work function change.

The parameter which shows the strongest dependence on the ITO surface treatments is the short circuit current. For the best surface treatment, short circuit current exhibits an order of magnitude increase compared to the untreated cell. It is likely that the surface treatments influence the concentration of traps and defects on the ITO surface and thus affect the carrier collection efficiency and short circuit current. Weak open circuit voltage dependence on the surface treatments could be explained by small differences in Fermi level alignment after the surface treatment or surface contamination removal. It was found that, for conventional device hierarchy, up to one order of magnitude improvement can be achieved with surface treatments.

Figure 2 shows the current voltage characteristics of the $\mathrm{ITO} / \mathrm{C}_{60}(40 \mathrm{~nm}) / \mathrm{CuPc}(40 \mathrm{~nm}) / \mathrm{Cu}$ solar cells with different ITO surface treatments. $\mathrm{Cu}$ was chosen as a metal electrode since it has larger work function than $\mathrm{Al}$, and base was used instead of acid for surface treatments of ITO in order to lower its work function. The AM1 power conversion efficiency $\eta$ for the cell fabricated on untreated substrate is $0.092 \%$, for UV ozone treated one $\eta=0.15 \%$, for UV ozone $+\mathrm{NaOH}$ treated cell $\eta=0.19 \%$, while $\eta=0.25 \%$ for mech. $+\mathrm{UV}$ ozone $+\mathrm{NaOH}$ treated one. It can be observed that in this case the influence of the surface treatment is not as significant as in the conventional hierarchy ( 2.5 times improvement for inverted structure, 10 times improvement for conventional structure). The fill factor, same as before, is not influenced by the ITO surface treatment. Open circuit voltage is weakly dependent on the surface treatment, similar to the cells with conventional hierarchy. Short circuit current is most significantly influenced by ITO treatment for both device structures investigated.

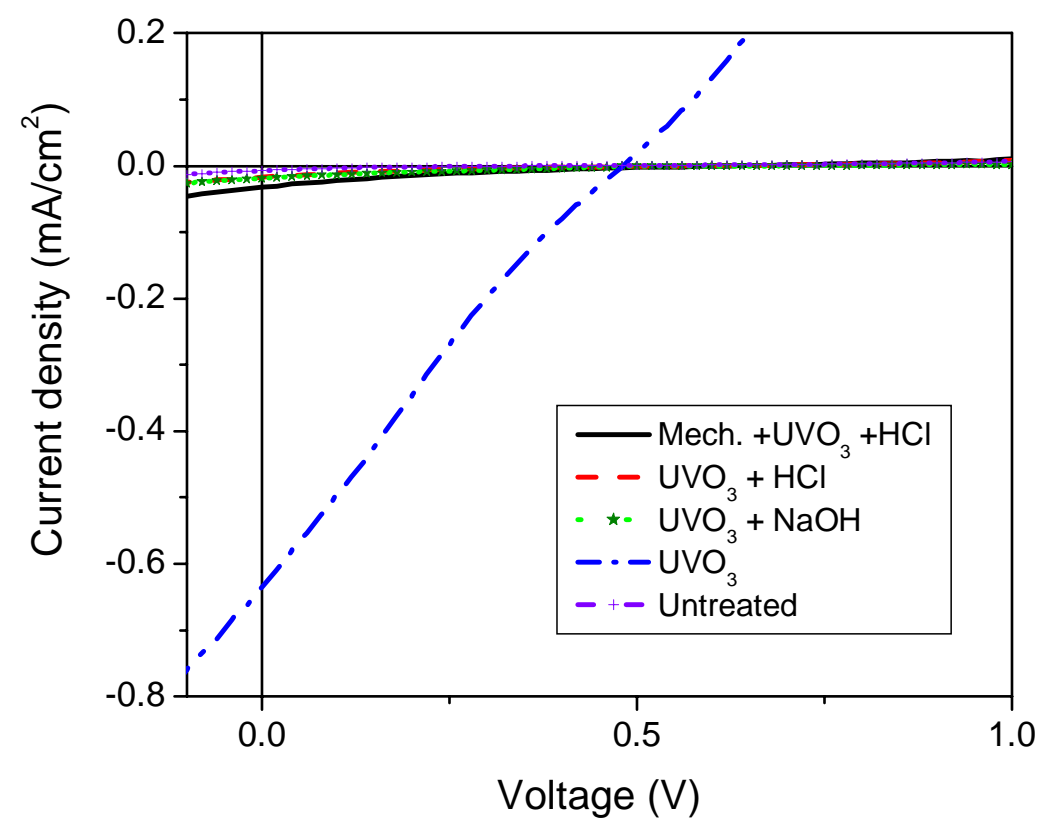

Fig. 3 The current-voltage characteristics of ITO/CuPc/PTCDI/Al cells with different ITO surface treatments under AM1 illumination. 
In order to verify whether the phenomena observed in comparison of different layer hierarchy in $\mathrm{CuPc} / \mathrm{C}_{60}$ cells apply to other material systems, we have also investigated influence of the layer hierarchy and ITO surface treatments for $\mathrm{CuPc/PTCDI}$ cells. The I-V characteristics under AM1 illumination for the conventional cell is shown in Fig. 3. The obtained AM1 power conversion efficiency is $0.0004 \%$ for untreated substrate, $0.07 \%$ for UV ozone, $0.001 \%$ for UV ozone $+\mathrm{HCl}, 0.02 \%$ for $\mathrm{UV}$ ozone $+\mathrm{NaOH}$, and $0.003 \%$ for mech. $+\mathrm{UV}$ ozone $+\mathrm{HCl}$ treated substrate. Also, fill factor is not affected by the ITO surface treatment in this structure. Open circuit voltage varies little between treatments. However, this variation does not seem to be related to ITO work function because the open circuit voltage for both $\mathrm{UV}+\mathrm{HCl}$ and $\mathrm{UV}+\mathrm{NaOH}$ is the same $(0.56 \mathrm{~V})$. Similar behavior to that of the $\mathrm{CuPc} / \mathrm{C}_{60}$ based cells can be observed. Suitable surface treatment improves the performance of the cell mainly through increase in the short circuit current and some increase of open circuit voltage compared to the untreated cell. However, it can be observed that the treatment which produces the best result is not the same for $\mathrm{ITO} / \mathrm{CuPc} / \mathrm{C}_{60} / \mathrm{Al}$ and $\mathrm{ITO} / \mathrm{CuPc} / \mathrm{PTCDI} / \mathrm{Al}$ cells. This is likely because the surface treatment can affect the growth of the organic layer and its surface morphology, and thus affects the interface between the two organic materials where the exciton dissociation takes place. For two different "n-type" materials, it is possible that the interface morphologies resulting in best exciton dissociation would be different. The current-voltage characteristics for ITO/PTCDI/CuPc/Cu cell is shown in Fig. 4. AM1 power conversion efficiency is $0.13 \%$ for untreated substrate, 0.41 for mech. $+\mathrm{UV}+\mathrm{NaOH}, 0.42 \%$ for $\mathrm{UV}$ ozone $+\mathrm{NaOH}, 0.42 \%$ for $\mathrm{UV}$ ozone. It can be observed that for this material system inverted device hierarchy again results in small difference between the ITO surface treatments and significantly higher power conversion efficiency compared to the conventional hierarchy.

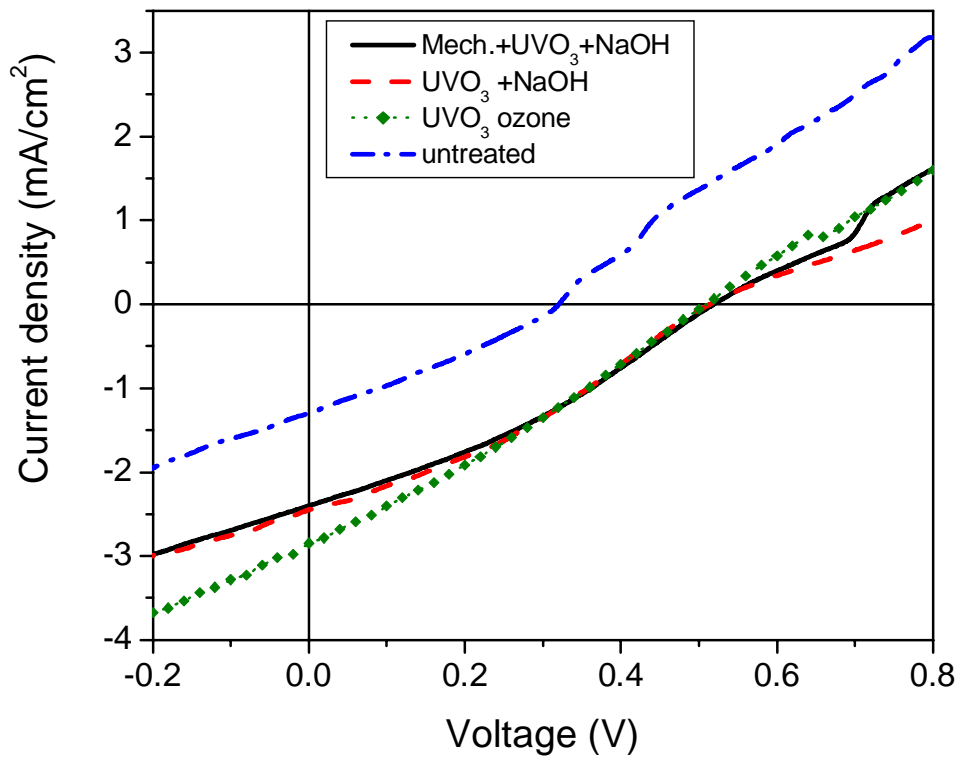

Fig. 4 The current-voltage characteristics of ITO/PTCDI/CuPc/Cu cells with different ITO surface treatments under AM1 illumination.

We also fabricated ITO/C $60(10 \mathrm{~nm}) / \mathrm{C}_{60}: \mathrm{CuPc}(1: 1)(60 \mathrm{~nm}) / \mathrm{CuPc}(10 \mathrm{~nm}) / \mathrm{Cu}$ solar cells with six different surface treatments, to try to elucidate how surface treatment influences the solar cell performance. Obtained results are shown in Fig. 5 and summarized in Table I. Fill factor, as expected, is not influenced by ITO treatment. It can be observed that the difference between the cell performance for UV ozone treatment only, UV ozone+NaOH, UV ozone+HCl, and mech.+UVozone $+\mathrm{NaOH}$ is very small, with power conversion efficiency varying from $0.35 \%$ for UV ozone only to $0.39 \%$ for mech.+UVozone $+\mathrm{NaOH}$ treatment. This indicates that the work function of the ITO is not a significant factor, since acid and base treatment have opposite signs of the work function change (increase for acid, decrease for base) ${ }^{4,5}$ However, changing the order of treatment appears to have significant influence on the cell performance. The $\mathrm{HCl}+\mathrm{UV}$ ozone and 
$\mathrm{NaOH}+\mathrm{UV}$ ozone treated cells show lower open circuit voltage and short circuit current, and overall lower efficiency even compared to the untreated cell. Furthermore, the cells with these two surface treatments are not very stable and the current voltage characteristics is not monotonous function. More detailed investigation of the ITO/organic interface is needed in order to draw any definite conclusions on the origin of observed phenomena. However, it seems reasonable to assume that lack of carbon contamination removal (performed by UV ozone) before chemical treatment is a reason for inferior performance of $+\mathrm{UV}$ ozone and $\mathrm{NaOH}+\mathrm{UV}$ ozone treated cells. It is possible that, if carbon contamination consisting mainly of organic hydrocarbons is not removed first, surface contamination will react with the chemical and result in interfacial layer containing traps and recombination centers which lower the carrier collection efficiency.

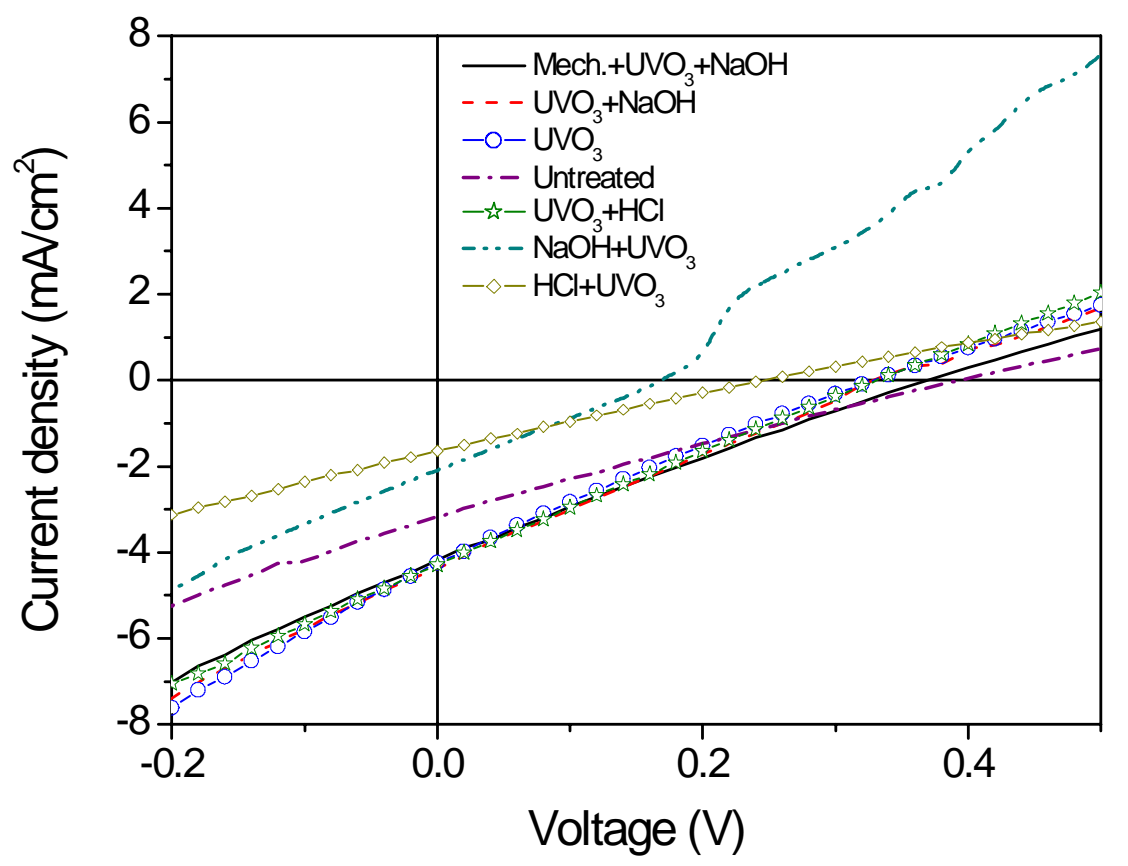

Fig. 5 The current-voltage characteristics of ITO/ $\mathrm{C}_{60} / \mathrm{CuPc}: \mathrm{C}_{60} / \mathrm{CuPc} / \mathrm{Cu}$ cells with different ITO surface treatments under AM1 illumination.

Table I Comparison of the ITO/ $\mathrm{C}_{60} / \mathrm{CuPc}: \mathrm{C}_{60} / \mathrm{CuPc} / \mathrm{Cu}$ solar cells parameters for different ITO treatments for AM1 $98 \mathrm{~mW} / \mathrm{cm}^{2}$ excitation.

\begin{tabular}{|c|c|c|c|c|c|c|c|}
\hline $\begin{array}{c}\text { Treatment / } \\
\text { parameter }\end{array}$ & untreated & UV ozone & $\begin{array}{c}\text { UV ozone }+ \\
\mathrm{NaOH}\end{array}$ & $\begin{array}{c}\mathrm{NaOH}+ \\
\text { UV ozone }\end{array}$ & $\begin{array}{c}\text { mech.+ } \\
\text { UV ozone }+ \\
\mathrm{NaOH}\end{array}$ & $\begin{array}{c}\text { UV ozone + } \\
\mathrm{HCl}\end{array}$ & $\begin{array}{c}\mathrm{HCl}+\mathrm{UV} \\
\text { ozone }\end{array}$ \\
\hline $\mathrm{I}_{\mathrm{sc}}\left(\mathrm{mA} / \mathrm{cm}^{2}\right)$ & 3.18 & 4.24 & 4.37 & 2.09 & 4.18 & 4.29 & 1.64 \\
\hline $\mathrm{V}_{\mathrm{oc}}(\mathrm{V})$ & 0.38 & 0.32 & 0.32 & 0.16 & 0.36 & 0.32 & 0.24 \\
\hline $\mathrm{FF}$ & 0.24 & 0.24 & 0.26 & 0.27 & 0.24 & 0.25 & 0.25 \\
\hline$\eta(\%)$ & 0.24 & 0.35 & 0.38 & 0.1 & 0.39 & 0.37 & 0.1 \\
\hline
\end{tabular}

We have shown that the organic solar cells with inverted cell hierarchy show higher power conversion efficiency and less sensitivity to the ITO properties. However, cleaning the ITO surface with UV ozone is necessary to improve the device performance in all cases. The work function of ITO does not appear to have significant influence on the solar cell 
performance for both conventional and inverted hierarchy. The parameter which is most affected by surface treatment is the short circuit current. This is likely due to removal of insulating carbon contamination layer on the ITO surface, as well as possible change in the concentration of defects and traps at the interface affecting the carrier collection efficiency. Further detailed study of the interface composition and chemistry is necessary to conclusively establish reasons for improved solar cell performance with ITO treatments, as well as clarify the differences in performance between the conventional and inverted device hierarchy.

\section{CONCLUSION}

In conclusion, we have fabricated organic solar cells using two different material combinations $\left(\mathrm{CuPc} / \mathrm{C}_{60}\right.$ and $\mathrm{CuPc} /$ PTCDI) in conventional and inverted device structure and investigated influence of the ITO surface treatments on the device structure. It was found that, in both cases, devices with inverted structure exhibit improved performance and less sensitivity to the ITO properties and surface treatments performed. Fill factor was not sensitive to device hierarchy and ITO surface treatments. Open circuit voltage was not affected by device hierarchy and showed weak dependence on ITO surface treatments. The parameter which was most significantly affected by the change of device hierarchy and surface treatments was the short circuit current. Observed differences have been attributed to the changes in carrier collection efficiency at ITO/organic interface.

\section{ACKNOWLEDGEMENTS}

This work has been supported by the RGC earmarked grant of Hong Kong (Project HKU 7075/01P, and HKU 7056/02E) and the University of Hong Kong University Research Committee seed funding grant.

\section{REFERENCES}

1. J. S. Kim, R. H. Friend, and F. Cacialli, "Surface energy and polarity of treated indium-tin-oxide anodes for polymer light-emitting diodes studied by contact-angle measurements", J. Appl. Phys. vol. 86, pp. 2774-2778, Sept. 1999.

2. J. S. Kim, F. Cacialli, A. Cola, G. Gigli, and R. Cingolani, "Increase of charge carriers density and reduction of Hall mobilities in oxygen-plasma treated indium-tin-oxide surfaces”, Appl. Phys. Lett. vol . 75, pp. 19-21, July 1999.

3. J. S. Kim, M. Granström, R. H. Friend, N. Johansson, W. R. Salaneck, R. Daik, W. J. Feast and F. Cacialli, "Indiumtin-oxide treatments for single- and double-layer polymeric light-emitting diodes: The relation between the anode physical, chemical, and morphological properties and the device performance", J. Appl. Phys. 84, pp. 6859-6870, Dec. 1998.

4. F. Nüesch, E. W. Forsythe, Q. T. Le, Y. Gao, and L. J. Rothberg, "Importance of indium tin oxide surface acido basicity for charge injection into organic materials based light emitting diodes”, J. Appl. Phys. 87, pp. 7973-7980, June 2000.

5. F. Nüesch, L. J. Rothberg, E. W. Forsythe, Q. T. Le, and Y. Gao, "A photoelectron study on the indium tin oxide treatment by acids and bases", Appl. Phys. Lett. 74 pp. 880-882, Feb. 1999.

6. F. Li, H. Tang, J. Shinar, O. Resto, and S. Z. Weisz, "Effects of aquaregia treatment of indium-tin-oxide substrates on the behavior of double layered organic light-emitting diodes", Appl. Phys. Lett. 70, pp. 2741-2743, May 1997.

7. S. K. So, W. K. Choi, C. H. Cheng, L. M. Leung, and C. F. Kwong, "Surface preparation and characterization of indium tin oxide substrates for organic electroluminescent devices”, Appl. Phys. A 68, pp. 447-450, April 1999.

8. K. Sugiyama, H. Ishii, Y. Ouchi, and K. Seki, "Dependence of indium-tin-oxide work function on surface cleaning method as studied by ultraviloet and x-ray photoemission spectroscopies”, J. Appl. Phys. 87, pp. 295-298, Jan. 2000.

9. M. Ishii, T. Mori, H. Fujikawa, S. Tokito and Y. Taga, "Improvement of organic electroluminescent device performance by in situ plasma treatment of indium-tin-oxide surface”, Journal of Luminescence 87-89, pp. 1165-1167, May 2000.

10. H. Y. Yu, X. D. Feng, D. Grozea, Z. H. Lu, R. N. Sodhi, A. M. Hor, and H. Aziz, "Surface electronic structure of plasma-treated indium tin oxides", Appl. Phys. Lett. 78, pp. 2595-2597, April 2001. 
11. C. Y. Kwong, A. B. Djurišić, P. C. Chui, L. S. M. Lam, and W. K. Chan, "Improvement of the efficiency of phthalocyanine organic Schottky solar cells with ITO electrode treatment", Appl. Phys. A 77, pp. 555-560, 2003.

12. P. Peumans and S. R. Forrest, "Very-high-efficiency double-heterostructure copperphthalocyanine/C 60 photovoltaic cells", Appl. Phys. Lett. 79, pp. 126-128, Jul. 2001.

13. T. Stübinger and W. Brütting, "Exciton diffusion and optical interference in organic donor-acceptor photovoltaic cells", J. Appl. Phys. 90, pp. 3632-3641, Oct. 2001.

14. H. Yonehara and C. Pac, "Photoelectrical properties of double-layer organic solar cells using C/sub 60/ and phthalocyanines", Thin Solid Films 278, pp. 108-113, May 1996.

15. P. Panayotatos, G. Bird, R. Sauers, A. Piechowski, and S. Husain, "An approach to the optimal design of p-n heterojunction solar cells using thin film organic semiconductors", Solar Cells 21, pp. 301-311, June-Aug. 1987.

16. A. J. Breeze, A. Salomon, D. S. Ginsley, B. A. Gregg, H. Tollmann, and H.-H. Hörhold, "Polymer-perylene diimide heterojunction solar cells", Appl. Phys. Lett. 81, pp. 3085-3087, Oct. 2002.

17. T. Tsuzuki, N. Hirota, N. Noma, and Y. Shirota, "Photoelectrical conversion of p-n heterojunction devices using thin films of titanyl phthalocyanine and a perylene pigment", Thin Solid Films 273, pp. 177-180, Feb. 1996.

18. J. B. Whitlock, P. Panayotatos, G. D. Sharma, M. D. Cox, R. R. Sauers, and G. R. Bird, "Investigations of materials and device structures for organic semiconductor solar cells", Optical Engineering 32, pp. 1921-1934, Aug. 1993. 